J. Asiat. Soc. Bangladesh, Sci. 44(1): 79-89, June 2018

\title{
PREVALENCE OF FUNGI WITH SEEDS OF TWENTY BRRI RELEASED RICE VARIETIES AND SEED QUALITY ANALYSIS*
}

\author{
TANIA SULTANA, S SHAMSI AND M A BASHAR ${ }^{1}$ \\ Department of Botany, University of Dhaka, Dhaka-1000, Bangladesh
}

\begin{abstract}
A total of 20 rice varieties of BRRI dhan 56 to BRRI dhan 75 were collected from Bangladesh Rice Research Institute (BRRI) for seed quality analysis, detection and identification of fungi associated with seeds of selected rice varieties. Dry inspection indicated that the percentage of pure seeds ranged from 90 - 100. The highest percentage of pure seed was found in BRRI dhan 66 and BRRI dhan 70 (100) and lowest in BRRI dhan 68 (90). A total of 21 fungal species were isolated from the selected rice varieties following "Blotter and Tissue Planting" methods. They were Alternaria padwickii, A. tenuissima, Aspergillus flavus, A. fumigatus, A. niger, A. ochraceus, A. clavatus, A. terreus, Bipolaris sorokiniana, B. spicifera, Chaetomium globosum, Curvularia lunata, Drechslera oryzae, Fusarium sp.1, Fusarium sp. 2, Nigrospora sp., Penicillium sp., Pestalotiopsis guepinii, Rhizopus stolonifer, Syncephalastrum racemosum and Trichoderma viride. Among them Penicillium sp., Drechslera oryzae, Aspergillus ochraceus, A. flavus, A. fumigatus, A. niger and Fusarium sp.1 were predominant in most of the rice varieties. In Tissue Planting method Drechslera oryzae showed the highest mean per cent frequency (6.69) and lowest was in the Bipolaris sorokiniana (0.41). Maximum total fungal association was recorded in variety BRRI dhan 61 (156.79\%) and minimum in BRRI dhan 66 (24.69\%). In Blotter method Penicillium sp. showed the highest mean per cent frequency (7.56) and lowest was in Rhizopus stolonifer (1.71). Maximum total fungal association was recorded in BRRI dhan $63(147.37 \%)$ and minimum in BRRI dhan $65(19.21 \%)$. Germination percentage of seeds was highest in BRRI dhan 66 (88) followed by BRRI dhan 67 (82), BRRI dhan 74 (80) and lowest in BRRI dhan69 (24). The percentage of seedling mortality was highest in BRRI dhan 63 (42) and lowest in BRRI dhan 74 (8.0) followed by BRRI dhan 67 (10). Correlation coefficient and regression analysis indicated that prevalence of fungi has significant effect on seed germination and seedling mortality. The present research work suggests that out of 20 BRRI rice varieties, BRRI dhan 65, BRRI dhan 66, BRRI dhan 67 and BRRI dhan 74 showed better performances on the basis of percentage of pure seed, fungal association, seed germination and seedling mortality.
\end{abstract}

Key words: Prevalence, Fungi, BRRI rice, Seed quality, Germination percentage

\footnotetext{
"A part of Ph.D.Thesis of first author. ${ }^{1}$ Author for correspondence: Email: botanybashar@yahoo.com
} 


\section{Introduction}

Rice (Oryza sativa L.) is one of the most important food crops mostly grown in tropical and sub-tropical climates. It is the main staple food of Bangladeshi people which covers $92 \%$ of food grain production and $75 \%$ of the total cultivable land (Ahmed et al. 2013). Among the rice growing countries, Bangladesh rank fourth to China, India and Indonesia both in acreage and production (Anon. 2003). The average per hectare production of rice in Bangladesh is extremely low as compared to other rice growing countries of the world (BBS 2012). Rice provides $76 \%$ of calorie and $66 \%$ of total protein requirement of daily food intake (Bhuiyan et al. 2002). In Bangladesh, more than 78 hybrid rice varieties are grown (Bhandari et al. 2011).

Rice suffers from more than 60 different diseases. In Bangladesh, 43 diseases are known to occur on the rice crop. Among them 27 are seed borne of which 14 are of major importance. Rice seed plays an important role to carry pathogen in quarantine. Fungi are the principal organisms associated with seed in storage. Of the seed borne diseases of rice, 22 are caused by fungi (Fakir et al. 2002). The destructive seed-borne fungal diseases of rice are brown spot (Drechslera oryzae and Bipolaris sorokiniana), bakanae (Fusarium moniliforme), blast (Pyricularia oryzae), sheath blight (Rizoctonia solani), sheath rot (Sarocladium oryzae) and stem rot (Sclerotium oryzae) cause yield reduction, quality deterioration and germination failure (Haque et al. 2007). To avoid the infection of foreign pathogen and to develop better rice variety, Bangladesh Rice Research Institute (BRRI) has been trying since last few decades. As a result 75 rice varieties have been released from BRRI since 2015 but information about the seed quality status of these rice varieties is inadequate. The storage fungi grow vigorously and initiate grain spoilage. These also bring about several undesirable changes making them unfit for consumption and sowing. So far no pathological investigation has been done on 20 (BRRI dhan 56 BRRI dhan 75) released rice varieties. Therefore, the present investigation was undertaken to find out seed borne mycoflora of the 20 BRRI released rice varieties and their seed quality status.

\section{Materials and Methods}

Seeds of 20 BRRI released rice varieties (BRRI dhan 56 to BRRI dhan 75) were collected from Genetic Resources and Seed Division of Bangladesh Rice Research Institute during January 2015 to July, 2016, were kept in brown paper bag and stored immediately in a dry safe place in the laboratory until used for the experiments. One hundred gm seeds of each sample were visually inspected to analyze the seed quality. In a clean laboratory table, the seeds of each working sample were separated and the seeds were separated then graded into different categories (Table 1). 
Per cent purity of seeds was determined according to the following formula (Khatun and Shamsi 2016):

$$
\text { Per cent purity of seed }=\frac{\text { Weight of pure seed }}{\text { Total weight of seed }} \times 100
$$

The fungi associated with rice seeds were isolated following "Tissue planting method" (Anon. 1968) and "Blotter method" (Anon. 1996).

Identification of the fungal isolates was determined based on morphological characteristics observed under a compound microscope following the standard literatures (Benoit and Mathur 1970, Booth 1971, Ellis 1971, 1976 and Barnett and Hunter 2000). Per cent frequency of the occurrence of the fungal isolates was calculated by adopting the formula of Spurr and Wetly (1972). Seedling mortality was determined after ten days of incubation by the formula of Anon. (2014).

Interrelationships among storage mycoflora, seed germination, purity and seedling mortality of different varieties of rice seeds were measured through correlation and regression analysis (Steel and Torrie 1960, Khatun and Shamsi 2016).

\section{Results and Discussion}

To analysis of seed quality, the percentage of normal and abnormal rice seeds is presented in Table 1. According to Seed Certification Agency (SCA) the accepted range of pure seed of rice is 96 to $99 \%$ in Bangladesh. Dry inspection indicated that the percentage of pure seeds ranged from 90 to 100 . The highest percentage of pure seed was found in the varieties of BRRI dhan 66 and BRRI dhan 70 (100) and lowest was recorded in BRRI dhan 68 (90). The highest percentage of spotted seed was recorded in the variety of BRRI dhan 62 (2.50) and lowest in BRRI dhan 68 (0.10). The highest percentage of discolored seeds was found in the variety of BRRI dhan 64 (6.25) and lowest in BRRI dhan 73 (0.20). The highest percentage of weed seeds was found in the variety of BRRI dhan $72(0.70)$ and lowest in BRRI dhan 64 (0.05). The highest percentage of inert materials was found in the variety of BRRI dhan 61 (1.30) and lowest in BRRI dhan 69 (0.10). 
Table 1. Per cent incidence of different types of rice seeds in dry seed inspection.

\begin{tabular}{|c|c|c|c|c|c|c|}
\hline \multicolumn{2}{|c|}{$\begin{array}{l}\text { Name of } \\
\text { varieties }\end{array}$} & $\begin{array}{l}\text { Pure } \\
\text { seed }\end{array}$ & $\begin{array}{c}\text { Spotted } \\
\text { seed }\end{array}$ & $\begin{array}{c}\text { Discolored } \\
\text { seed }\end{array}$ & $\begin{array}{l}\text { Weed } \\
\text { seeds }\end{array}$ & $\begin{array}{c}\text { Inert } \\
\text { materials }\end{array}$ \\
\hline \multicolumn{2}{|c|}{ BRRI dhan 56} & 98.00 & 0.40 & 1.00 & - & 0.60 \\
\hline " & $" 57$ & 99.00 & - & 1.00 & - & - \\
\hline$"$ & " 58 & 97.00 & 0.60 & 1.50 & 0.50 & 0.40 \\
\hline$"$ & ” 59 & 99.00 & - & 1.00 & - & - \\
\hline$"$ & $" 60$ & 92.00 & 2.00 & 5.00 & 0.10 & 0.90 \\
\hline$"$ & " 61 & 94.00 & 1.70 & 3.00 & - & 1.30 \\
\hline$"$ & " 62 & 92.00 & 2.50 & 4.50 & 0.50 & 1.50 \\
\hline$"$ & $" 63$ & 98.00 & - & 1.90 & - & 0.10 \\
\hline$"$ & $" 64$ & 92.00 & 0.50 & 6.25 & 0.05 & 1.20 \\
\hline$"$ & $" 65$ & 92.00 & 0.40 & 1.20 & 0.30 & 0.20 \\
\hline$"$ & " 66 & 100 & - & - & - & - \\
\hline$"$ & " 67 & 99.00 & - & 1.00 & - & - \\
\hline$"$ & " 68 & 90.00 & 0.10 & 9.40 & - & 0.50 \\
\hline$"$ & $" 69$ & 96.00 & 0.20 & 1.30 & 0.20 & 0.10 \\
\hline$"$ & $" 70$ & 100 & - & - & - & - \\
\hline$"$ & " 71 & 99.00 & - & 1.00 & - & - \\
\hline$"$ & " 72 & 99.00 & - & 0.30 & 0.70 & - \\
\hline$"$ & " 73 & 99.00 & - & 0.20 & - & 0.80 \\
\hline$"$ & ” 74 & 99.00 & - & 1.00 & - & - \\
\hline$"$ & $" 75$ & 98.00 & 0.20 & 1.10 & - & 0.70 \\
\hline
\end{tabular}

Naher et al. (2016) made dry seed inspection on BR11, BRRI dhan 30 and BRRI dhan 33 rice varieties. They reported that out of three varieties the highest percentage (83.35) of pure seed was in BRRI dhan 30. They also reported that the lowest percentage of spotted (2.75) and discolored seed (2.16) was in BRRI dhan 30 and BR11, respectively.

A total of 21 seed borne fungi were isolated from the selected BRRI rice varieties following tissue planting method (Table 2). The highest frequency percentage of A. padwickii and P. guepenii was noticed in BRRI dhan 60; A. tenuissima, A.flavus, A. terreus and S. racemosum on BRRI dhan 74, A. fumigatus, B. spicifera, Fusarium sp. 1 on BRRI dhan 73, A. niger and Fusarium sp. 2 in BRRI dhan 65, D. oryzae and Penicillium sp. in BRRI dhan 61, A.clavatus on BRRI dhan 75, C.globosum in BRRI dhan 56, C. lunata and Nigrospora sp. in BRRI dhan 63, R. stolonifer in BRRI dhan 67 and T. viride in BRRI dhan 63. Among these fungi D. oryzae, A. ochraceus, A. flavus, Penicillium sp. and A. fumigatus were predominant in most of the rice varieties (Table 2).

More than ten species of fungi were found to be associated with BRRI dhan 57, BRRI dhan 61 and BRRI dhan 63 varieties (Table 2). Maximum total fungal association was recorded in BRRI dhan 61 (156.79\%), BRRI dhan63 (136.5\%), BRRI dhan 60 (130.5) BRRI dhan 57 (108.52\%) and BRRI dhan 74 (104.49\%) whereas minimum was 


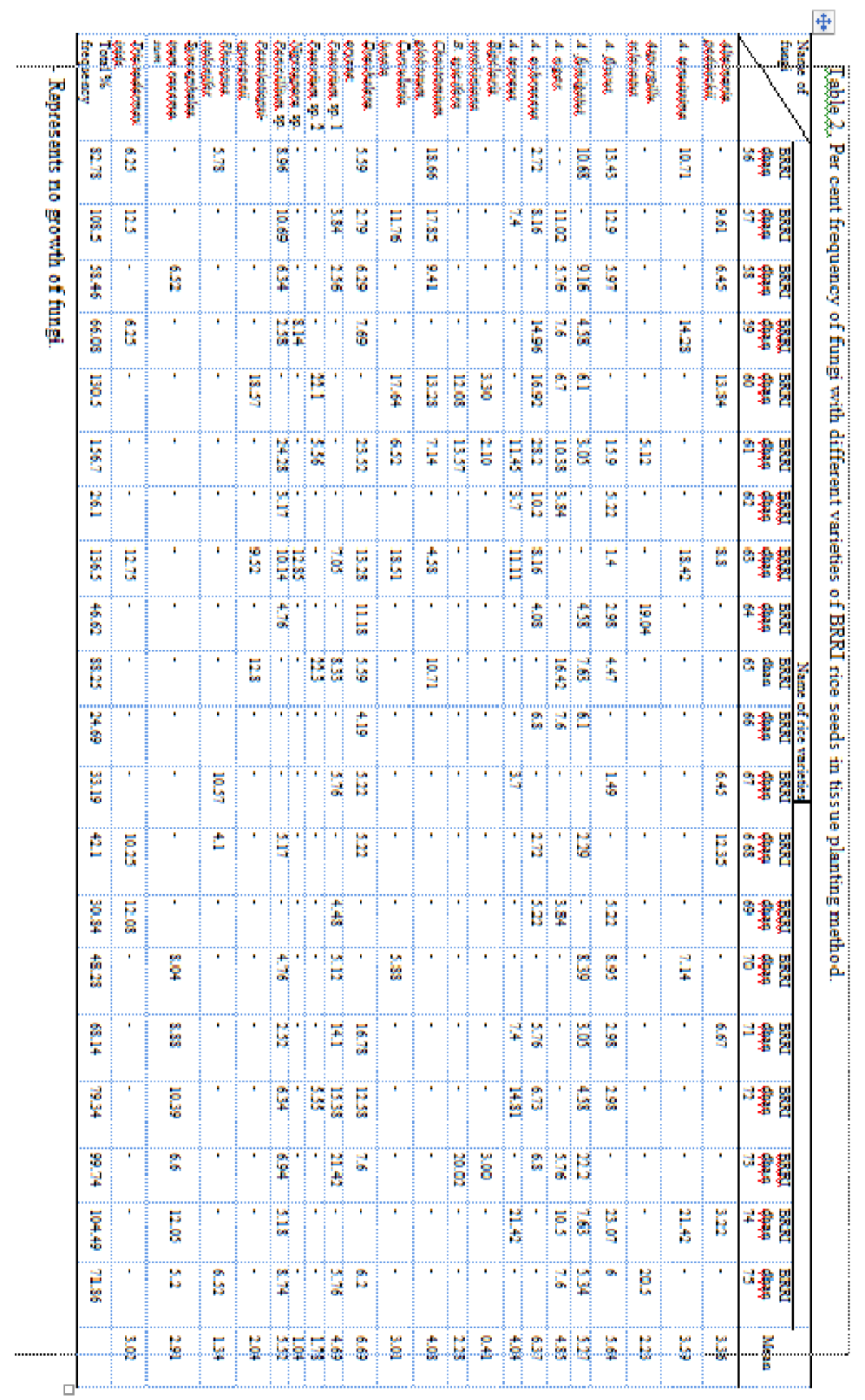


in BRRI dhan 69 (30.84\%), BRRI dhan 62 (26.13\%) and BRRI dhan 66 (24.69\%). In tissue planting method, Ora et al. (2011) found ten seed borne pathogens viz., Alternaria tenuissima, Aspergillus flavus, A. niger, Bipolaris oryzae, Curvularia lunata, Fusarium moniliforme, Penicillium sp., Nigrospora oryzae, Rhizopus stolonifer and Xanthomonas spp. associated with rice seeds. The highest incidence of Xanthomonas spp. was noticed on Tinpata whereas Bipolaris oryzae on Aloron, Fusarium moniliforme on ACI-1, Rhizopus stolonifer on Tia, Alternaria tenuissima on Hira-1, Curvularia lunata on Aloron, Penicillium sp. and Aspergillus flavus on BRRI hybrid dhan-1, Aspergillus niger on Taj-1 were observed. Nigrospora sp. was recorded only on Hira-1. Of all the pathogens Xanthomonas spp., Bipolaris oryzae, Aspergillus sp., Fusarium moniliforme and Rhizopus stolonifer were predominant.

In blotter method a total of 17 seed borne fungi were isolated from the selected BRRI rice varieties (Table 3). The highest frequency percentage of $A$. padwickii and T. viride was noticed in BRRI dhan 67; Aspergillus niger in BRRI dhan 56, A. flavus on BRRI dhan 68, A. fumigatus in BRRI dhan 64, A. terreus, A. ochraceus and C. globosum in BRRI dhan 61, B. sorokiniana and P. guepenii in BRRI dhan 71, C. lunata and Fusarium sp. 2 in BRRI dhan 63, D. oryzae and R. stolonifer in BRRI dhan 72, Fusarium sp.1 and $S$. racemosum in BRRI dhan 74 and Penicillium sp. in BRRI dhan 60 varieties (Table 3 ). Penicillium sp. showed the highest mean frequency percentage (7.56) of infection in 20 rice varieties which was followed by A. fumigatus (6.79), A. flavus (5.86), D. oryzae (5.24), A. ochraceus (4.99). Maximum total fungal association was recorded in BRRI dhan 63 (147.3\%) whereas minimum was in BRRI dhan 65 (19.21\%) variety.

Rahman et al. (2000) identified Bipolaris oryzae, Trichoconis padwickii, Curvularia lunata, Nigrospora oryzae, Alternaria tenuis, Aspergillus spp. and Penicillium spp. in BR 11 variety. Gopalakrishnan et al. (2010) conducted an experiment in India to identify the seed borne pathogen associated with rice seed and they recorded eight genera of fungi viz., Alternaria, Aspergillus, Bipolaris, Chaetomium, Curvularia, Fusarium, Sarocladium and Trichoderma comprising 12 species. Among them, the most predominant one was Bipolaris oryzae which was associated with $58.89 \%$ seed samples followed by Alternaria padwickii (52.96). In blotter method, Naher et al. (2016) detected six fungal species viz., Alternaria padwickii, Aspergillus spp., Bipolaris oryzae, Curvularia lunata Fusarium moniliforme and Fusarium oxysporum from the 3 rice varieties such as BR11, BRRI dhan 30 and BRRI dhan 33. In blotter method, Ora et al. (2011) found 12 seed borne pathogens viz., Alternaria tenuissima, Aspergillus spp, Bipolaris oryzae, Chaetomium globosum, Curvularia lunata, Fusarium moniliforme, Penicillium sp., Phoma sp., Nigrospora oryzae, Rhizopus stolonifer, Tilletia barclyana and Xanthomonas oryzae. Of all the pathogens Xanthomonas spp, Rhizopus stolonifer, Aspergillus spp. Bipolaris oryzae and Fusarium moniliforme were predominant. 


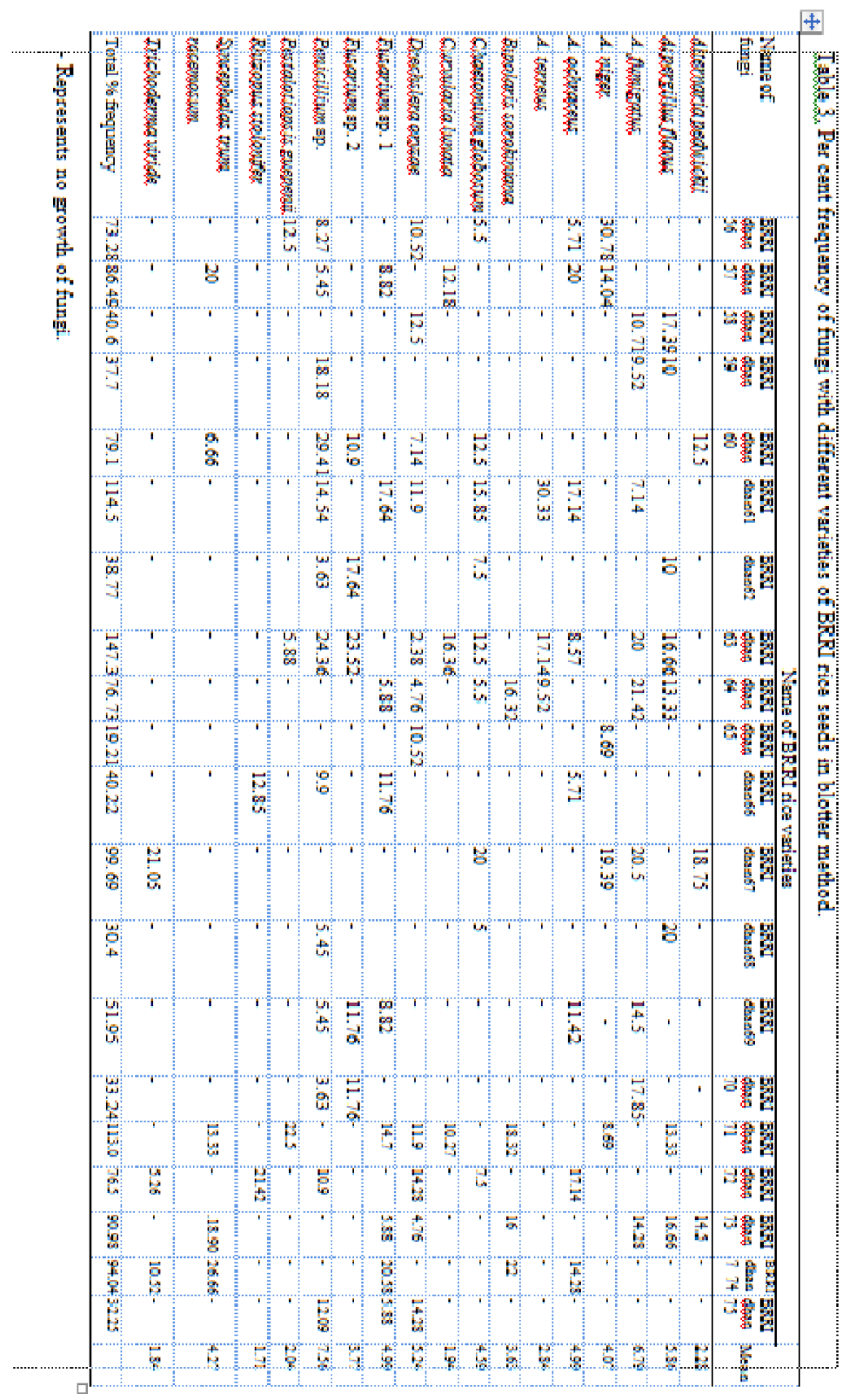


The fungal association with rice seeds also effects germination, seedling mortality as well as seedling height (Table 4). Among twenty varieties, in BRRI dhan 74, the germination percentage was highest (98\%) and in BRRI dhan 62 this was lowest (25\%). The highest mortality percentage value of rice seedling was found in BRRI dhan $62(16 \%)$ and the lowest value was found in BRRI dhan 74 (2.04\%). The length of root was highest in BRRI dhan $72(5.37 \mathrm{~cm})$ and lowest in BRRI dhan $62(2.20 \mathrm{~cm})$, whereas shoot length was highest in BRRI dhan $73(8.97 \mathrm{~cm})$ and lowest in BRRI dhan $67(4.56 \mathrm{~cm})$.

Table 4. Per cent germination, seedling mortality and seedling height of rice seeds after ten days of incubation.

\begin{tabular}{|c|c|c|c|c|c|c|}
\hline \multirow{2}{*}{\multicolumn{3}{|c|}{$\begin{array}{l}\text { Name of } \\
\text { varieties }\end{array}$}} & \multirow{2}{*}{$\begin{array}{c}\text { Germination } \\
(\%)\end{array}$} & \multirow{2}{*}{$\begin{array}{l}\text { Mortality } \\
(\%)\end{array}$} & \multicolumn{2}{|c|}{ Seedling height $(\mathrm{cm})$} \\
\hline & & & & & Root & Shoot \\
\hline \multicolumn{3}{|c|}{ BRRI dhan 56} & 82 & 7.30 & 4.26 & 5.50 \\
\hline ” & 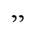 & 57 & 60 & 13.34 & 4.33 & 5.37 \\
\hline ” & $"$ & 58 & 78 & 5.12 & 4.00 & 5.40 \\
\hline$”$ & $"$ & 59 & 72 & 4.16 & 4.92 & 7.58 \\
\hline$”$ & $”$ & 60 & 64 & 9.37 & 3.25 & 7.30 \\
\hline$”$ & $”$ & 61 & 46 & 15.22 & 3.33 & 6.66 \\
\hline 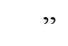 & 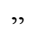 & 62 & 25 & 16.00 & 2.20 & 7.82 \\
\hline$”$ & $”$ & 63 & 35 & 8.58 & 3.30 & 6.62 \\
\hline$"$ & $"$ & 64 & 72 & 10.77 & 2.33 & 6.60 \\
\hline$”$ & $"$ & 65 & 65 & 6.06 & 3.39 & 5.55 \\
\hline$”$ & $"$ & 66 & 94 & 3.19 & 5.00 & 5.90 \\
\hline$”$ & $"$ & 67 & 80 & 6.25 & 2.49 & 4.56 \\
\hline$"$ & $"$ & 68 & 74 & 5.40 & 2.21 & 5.00 \\
\hline$"$ & $"$ & 69 & 46 & 10.86 & 3.27 & 5.69 \\
\hline$"$ & $"$ & 70 & 96 & 5.20 & 4.39 & 7.22 \\
\hline$"$ & $"$ & 71 & 78 & 3.84 & 5.22 & 8.83 \\
\hline$"$ & $"$ & 72 & 88 & 4.54 & 5.37 & 8.29 \\
\hline$"$ & $"$ & 73 & 78 & 6.41 & 5.19 & 8.97 \\
\hline " & $"$ & 74 & 98 & 2.04 & 4.82 & 8.31 \\
\hline$"$ & $"$ & 75 & 76 & 7.90 & 4.48 & 8.00 \\
\hline
\end{tabular}

In case of Tissue Planting method Fig. IA shows the relationship between percentage of germination rate and occurrence of fungi and negative correlation between the two variables. Here regression line gives a downward sloping curve which means that germination of seeds decreases when the percentage of fungi increases or the germination of seed increases when the percentage of fungi decreases. In the present study, the correlation co-efficient value between percentage of fungi and percentage of germination was +0.216 . Fig. 1B shows the relationship between occurrence of fungi and seedling mortality and positive correlation between the two variables. Here regression line gives an upward sloping curve which means that both the variable change in the same direction i.e. the mortality of seeds increases when the percentage of fungi increases. The correlation coefficient value between percentage of fungi and seedling mortality was +0.212 . 


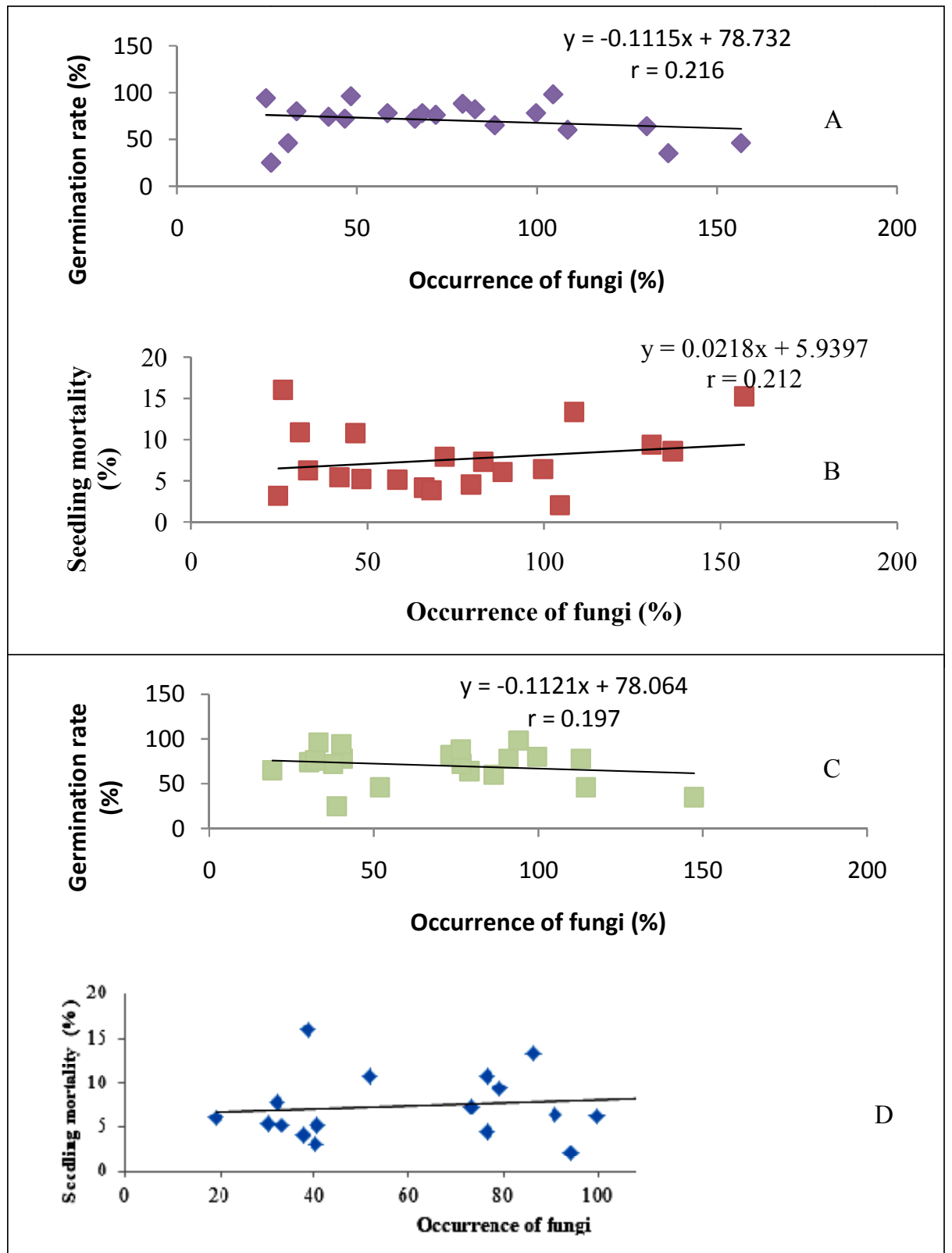

Fig. 1. For tissue planting method (A - B) correlation coefficient and regression equation between $\mathrm{A}=$ Germination rate $(\%)$ and occurrence of fungi $(\%), \mathrm{B}=$ Seedling mortality $(\%)$ and occurrence of fungi (\%); For blotter method (C - D) correlation coefficient and regression equation between $\mathrm{C}=$ Germination rate $(\%)$ and occurrence of fungi $(\%), \mathrm{D}=$ Seedling mortality (\%) and occurrence of fungi $(\%)$. 
Similarly, for blotter method Fig. IC shows the relationship between percentage of germination rate and occurrence of fungi and negative correlation between the two variables. Here regression line gives a downward sloping curve which means that germination of seeds decreases when the percentage of fungi increase or the germination of seeds increases when the percentage of fungi decrease. In the present study, the correlation co-efficient value between percentage of fungi and percentage of germination was +0.197 . Fig. 1D shows the relationship between occurrence of fungi and seedling mortality and positive correlation between the two variables. Here regression line gives an upward sloping curve which means that both the variable change in the same direction i.e. the mortality of seeds increases when the percentage of fungi increases. The correlation coefficient value between percentage of fungi and seedling mortality was $+0.153$

In the present work a total of 21 fungal species were isolated from the seeds of selected twenty BRRI released rice varieties. Among these fungi Penicillium sp., Drechslera oryzae, Aspergillus ochraceus, A. flavus, A. fumigatus, A. niger and Fusarium sp.1 were predominant in most of the rice varieties. The present work also showed that occurrence of fungi had significant effect on the seed germination and seedling mortality. On the basis of percentage of purity, fungal association, seed germination and seedling mortality BRRI dhan 65, BRRI dhan 66, BRRI dhan 67 and BRRI dhan 74 showed better results out of 20 BRRI released rice varieties.

\section{Acknowledgement}

The first author (TS) expresses her heartfelt gratitude to the authority of the Ministry of Science and Technology, Government of the People's Republic of Bangladesh for providing financial assistance to cary out this work through Bangobandhu Science and Technology Fellowship program.

\section{References}

Ahmed, M., M. Hossain, K. Hassan and C.K. Dash. 2013. Efficacy of different plant extract on reducing seed borne infection and increasing germination of collected rice seed sample. Universal Journal of Plant Science 1(3): 66-73.

Anonymous. (Commonwealth Agricultural Bureau), 1968. Plant pathologist's pocket book. $1^{\text {st }}$ edition. The Commonwealth Mycological Institute, England. pp. 267.

Anonymous. 1996. International rules of seed testing assoc. In: Proc. Int. Seed Test. Assoc. pp. 1941.

Anonymous. 2003. Production Yearbook, Food and Agriculture Organization, Rome, Italy, Vol. 56.

Anonymous. 2014. International Rules for Seed Testing. International Seed Testing Association, Switzerland. pp. 10.

BBS 2012. The Statistical Yearbook of Bangladesh (BBS). Ministry of Planning. The People's Republic of Bangladesh. pp. 468. 
Barnett, H.L. and B.B. Hunter. 2000. Illustrated Genera of Imperfect Fungi. $4^{\text {th }}$ edn., Burges Pub., Co. Minneapolis. pp. 185.

Benoit, M.A. and S.B. Mathur.1970. Identification of species Curvularia on rice seed. Proc. Inst. Seed Test. Assoc. 35(1): 1-23.

Bhandari, H., S. Mohanty and M. Mossain. 2011. Hybrid Rice in Bangladesh: Current Status and Future Project. In: Proceedings of the $7^{\text {th }}$ ASAE Conference 2011, Hanoi, Vietnam. pp. 13-15.

Bhuiyan, N.I., D.N.R. Paul and M.A. Jabber. 2002. Feeding the extra millions by 2025 - challenges for rice research and extension in Bangladesh. A key note paper presented in the National Workshop on Rice Research and Extension-2002 held at BRRI, Gazipur, Bangladesh.

Booth, C. 1971. The genus Fusarium. The Commonwealth Mycological Institute, England. pp. 267.

Ellis, M.B. 1971. Dematiaceous hyphomycetes. The Commonwealth Mycological Institute, England. pp. 608.

Ellis, M.B. 1976. More Dematiaceous hyphomycetes. The Commonwealth Mycological Institute, England, 507. pp.

Fakir, G.A., I. Hossain, M.U. Ahmad, M. Asad-ud-Doullah and M. Alam. 2002. Quality of farmer's Boro and T. Aman rice seeds collected before sowing from Bogra, Rajshahi and Rangpur Districts of Bangladesh. A paper presented in the review and planning meeting of the rice seed health improvement (PETRRA) project, held on 21-22 April at BRRI, Gazipur, Bangladesh.

Gopalakrishnan, C., A. Kamalakannan and V.Valluvaparidasan. 2010. Survey of seed-borne fungi associated with rice seeds in Tamil Nadu, India. Libyan Agric. Res. Cen. J. Intl.1(5): 307-309.

Haque, A.H.M.M., M.A.H. Akhon, M.A. Islam, K.M. Khalequzzaman and M.A. Ali. 2007. Study on seed health, germination and seedling vigor of farmers produced rice seeds. Intl. J. Sustain. Crop Prod. 2(5): 34-39.

Khatun, A. and S. Shamsi. 2016. Estimation of interrelationship among seed germination, purity, seedling mortality and association of fungi with seeds of chickpea. Bangladesh J. Bot.45(3): 693-698.

Naher, L., M.A. Aliand S. Sheheli. 2016. Effect of seed treatment on seed borne fungi of rice. Progressive Agriculture 27: 48-56.

Ora N., A.N. Faruq, M.T. Islam, N. Akhtar and M.M. Rahman. 2011. Detection and identification of seed borne pathogens from some cultivated hybrid rice varieties in Bangladesh. MiddleEast Journal of Scientific Research 10 (4): 482-488.

Rahman, A.J.M.K., M.M. Islam and M.A.T. Mia. 2000. Evaluation of cleaning methods to improve the quality of farmer's saved rice seed. Bangladesh J. Plant Pathol.16 (1\& 2): 39- 42.

Spurr, H.W.J. and R.E. Wetly. 1972. Incidence of tobacco leaf microflora in relation to brown spot disease and fungicidal treatment. Phytopathol. 62: 916-920.

Steel, R.G.D. and J.H. Torrie 1960. Principles and Procedures of Statistics. McGraw-Hill Book Co., New York, pp. xvi +481. 